\title{
Vascular remodeling in adults after coarctation repair: impact of descending aorta stenosis and age at surgery
}

\author{
Olga Trojnarska $\cdot$ Ludwina Szczepaniak-Chicheł $\cdot$ Katarzyna Mizia-Stec • \\ Marcin Gabriel • Agnieszka Bartczak - Stefan Grajek - Zbigniew Gąsior • \\ Lucyna Kramer • Andrzej Tykarski
}

Received: 6 April 2010/Accepted: 29 November 2010/Published online: 16 December 2010

(C) The Author(s) 2010. This article is published with open access at Springerlink.com

\begin{abstract}
Background Patients after successful repair of coarctation of aorta ( $\mathrm{CoAo})$ are at risk of hypertension at rest and associated end-organ damage. The aim of the study was to assess arterial stiffness and function in adults after coarctation repair in relation to descending aorta (AoD) residual coarctation and patient's age at operation.

Methods 85 patients after CoAo repair (53 males) aged $34.6 \pm 10.3$ years; median age at operation $0.9 \pm$ 8.2 years. The control group-30 individuals (18 males) at mean age $33.6 \pm 8.2$ years. The following central parameters: augmentation pressure (AP) and augmentation index (AI) as well as peripheral vascular parameters:
\end{abstract}

O. Trojnarska $(\bowtie) \cdot$ A. Bartczak · S. Grajek

1st Department of Cardiology, Poznań University of Medical

Sciences, Poland, ul. Długa 1/2, 61-848 Poznań, Poland

e-mail: olgatroj@wp.pl

L. Szczepaniak-Chicheł · A. Tykarski

Department of Hypertensiology, Angiology and Internal

Medicine, Poznań University of Medical Sciences,

Poznań, Poland

K. Mizia-Stec $\cdot$ Z. Gąsior

Department of Cardiology, Medical University of Silesia,

Katowice, Poland

M. Gabriel

Department of General and Vascular Surgery, Poznań University of Medical Sciences, Poznań, Poland

L. Kramer

Department of Computer Sciences and Statistics, Poznań

University of Medical Sciences, Poznań, Poland flow-mediated dilatation (FMD), nitroglycerin-mediated vasodilatation (NMD), intima-media thickness (IMT) and pulse wave velocity (PWV) were measured.

Results 47 CoAo-repaired patients were normotensive, and compared to control, they presented higher values of central parameters AP $(7.3 \pm 4.6$ vs. $4.4 \pm 3.6 \mathrm{mmHg}$; $p=0.002)$ and $\mathrm{AI}(18.6 \pm 10.4$ vs. $13.5 \pm 4.3 \%$; $p=0.03)$; as well as the increased $\mathrm{PWV}(6.8 \pm 1.2$ vs. $5.4 \pm 0.9 \mathrm{~m} / \mathrm{s} ; p=0.003)$, while IMT was comparable $(0.53 \pm 0.01$ vs. $0.51 \pm 0.01 \mathrm{~mm} ; p=0.06)$. The vasodilatation was impaired in the normotensive patients: FMD $(4.8 \pm 2.8$ vs. $8.5 \pm 2.3 \% ; p=0.00003)$ and $\mathrm{NMD}$ $(11.3 \pm 4.6$ vs. $19.8 \pm 7.2 \% ; p=0.00001)$. The comparison of recoarctation $(46,54 \%)$ to non-recoarctation (39, $46 \%)$ patients did not reveal any significant differences in resting systolic and diastolic pressures, as well as the values of $\mathrm{AI}$ and the peripheral vascular parameters; the value of AP was higher in the recoarctation patients $(10.5 \pm 6.9$ vs. $7.5 \pm 4.1 ; p=0.02)$ and correlated positively with the gradient across AoD $(r=0.295$, $p=0.01$ ). There was no significant linear correlation between age at the time of surgery and any of peripheral arterial parameters.

Conclusions Residual stenosis in AoD does not affect the arterial vasodilatation nor stiffness in patients after CoAo repair. Early operation has no impact on peripheral vascular remodeling or central pressure which supports the claim that coarctation of the aorta is a systemic vascular disorder which leads to progressive vascular and end-organ damage despite early correction.

Keywords Adult congenital heart disease - Flow mediated dilatation (FMD) - Pulse wave velocity (PWV) . Intima-media thickness (IMT) · Augmentation index (AI) Coarctation of aorta (CoAo) 


\section{Introduction}

Surgical correction of aortic coarctation (CoAo) has been successfully performed for over half of the century. Life expectancy remains to be reduced in patients with this congenital heart disease even after successful repair. The main predictors of unfavorable prognosis in that group of patients are arterial hypertension ( $\mathrm{AH})$ with subsequent end-organ damage, and an inclination for development of early atherosclerosis [1-8]. The pathophysiology of hypertension that occurs after coarctation repair is still a matter of debate.

Despite successful removal of residual stenosis in the descending aorta (AoD), hypertension is still present in $30-50 \%$ of patients, which suggests that CoAo might not be the simple mechanical obstruction of the main artery but more likely a widespread anomaly of the cardiovascular system $[3,4,8,10,11]$. At the same time most of the available data suggests that prognosis is strongly affected by the age at the surgery; $\mathrm{AH}$ is less frequent in patients who have undergone coarctation repair in infancy [5, 7, 8, 12-16]. Many researchers point out that early detection and treatment of stenosis of the AoD is associated with better outcomes, since this condition plays a significant role in the pathway leading to AH $[5,17,18]$. Functional and histopathological studies proved increased stiffness of the precoarctation part of the aorta $[19,20]$. According to the majority of publications, this phenomenon forms the basis for complex interactions present in $\mathrm{CoAo}$ - functional abnormalities in vascular reactivity and baroreceptor-reflex function, as well as irreversible arterial remodeling-all leading to hypertension in the studied population [3, 5, 21]. Elucidation of potential mechanisms underlying vascular remodeling, representing increased vascular stiffness and altered reactivity in CoAo, brings us closer in understanding the pathophysiology of hypertension in those patients. It is justified, in our opinion, to carry out the analysis of significance of residual gradient across AoD for vascular remodeling and the influence exerted by the age at intervention.

The aim of the study was to evaluate arterial stiffness and function in adult patients after coarctation repair, in relation to residual gradient across AoD as well as age at the operation.

\section{Materials and methods}

The study population consisted of 85 coarctation-repaired patients (53 males) aged 19-64 years (mean $34.6 \pm$ 10.3 years) who had undergone operation at the age of $0.5-34$ years (10.9 \pm 8.2 years), cared by our adult congenital heart disease outpatient clinic. The control group consisted of 30 healthy individuals (18 males) aged 24-48 $(33.6 \pm 8.2$ years). Most patients in the study group -74
(87\%) had undergone Dacron patch repair by the same cardiac surgeon; 4 (5\%) had undergone subclavian flap aortoplasty, 7 (8\%) - end-to-end anastomosis. Two patients received aortic prosthetic valve (St. Jude Medical). Nine patients had undergone reoperation due to restenosis of the AoD, two patients had received non-invasive treatment of recoarctation, another one had undergone stent-graft implantation into the AoD due to aneurysm. The following congenital heart diseases were additionally diagnosed: bicuspid aortic valve without functional abnormality $(n=25,29.4 \%)$, surgically repaired ventrivular septal defect $(n=6,7.1 \%)$, occluded persistent arterial duct $(n=5,5.9 \%)$, and trivial mitral insufficiency $(n=21,24.7 \%)$.

In order to avoid confounding factors which might influence the vascular parameters, the following exclusion criteria were established: acute and chronic inflammatory diseases (in the preceding 3 months), underlying malignancies, cigarette smoking within $12 \mathrm{~h}$ before the examination, diabetes mellitus. The investigators performing the assessment of the peripheral and central vessel parameters were blinded to results of the echocardiographic examination.

Clinical characteristics of the study population, including separately demographic and biochemical data for normotensive patients, are presented in Table 1 .

A cuff sphygmomanometer was used to measure blood pressure at rest in all participants. Arterial hypertension was recognised if the values of blood pressure exceeded $140 / 90 \mathrm{mmHg}$, or a report of a prior diagnosis of hypertension and current antihypertensive treatment, in accordance with the guidelines established in 2007 by the European Society of Hypertension and the European Society of Cardiology [15]. The study involved both patients on antihypertensive therapy and patients from whom antihypertensive therapy was withdrawn for at least $48 \mathrm{~h}$ before the study [22].

Echocardiographic examination was performed using Vivid 7 (GE Healthcare) with $2.5 \mathrm{MHz}$ probe in 2D, M and Doppler modes. The single investigator evaluated cardiac anatomy and left ventricular systemic function (Simpson biplane method), normal systolic function was a criterion for inclusion in the study. The severity of residual stenosis of the AoD was determined by evaluation of the suprasternal notch. Restenosis was diagnosed when the AoD pressure gradient was equal to or greater than $20 \mathrm{mmHg}$ and rest arm-leg systolic blood pressure gradient exceeded $20 \mathrm{mmHg}$. Based on those measurements, the study population was divided into subgroups with residual aortic stenosis $[\mathrm{AoD}(+)]$ and without it $[\mathrm{AoD}(-)][17]$.

A clinical characteristics of patients with recoarctation as well as patients without residual stenosis in the AoD (both demographic and biochemical data) is presented in Table 3. 
Table 1 Baseline characteristics of the study population and the control group

\begin{tabular}{|c|c|c|c|c|c|}
\hline & $\begin{array}{l}\text { CoAo } \\
(N=85)\end{array}$ & $\begin{array}{l}\text { CoAo } \mathrm{AH}(-) \\
(N=47)\end{array}$ & $\begin{array}{l}\text { Controls } \\
(N=30)\end{array}$ & $\begin{array}{l}p \text { CoAo } \\
\text { versus controls }\end{array}$ & $\begin{array}{l}p \text { CoAo } \mathrm{AH}(-) \\
\text { versus controls }\end{array}$ \\
\hline Male:female & $53: 32$ & $30: 17$ & $18: 12$ & 0.99 & 0.81 \\
\hline $\begin{array}{l}\text { Age (years), mean } \pm \mathrm{SD} \\
\text { (median; range) }\end{array}$ & $34.6 \pm 10.3(33 ; 18-64)$ & $33.7 \pm 8.2(33 ; 18-60)$ & $33.6 \pm 8.2(32 ; 18-61)$ & 0.8 & 0.92 \\
\hline Age at surgery (years) & $10.9 \pm 8.2$ & $10.8 \pm 7.6$ & - & - & - \\
\hline Smokers (current) & $6(7 \%)$ & $4(8 \%)$ & $2(6.5 \%)$ & 0.61 & 0.46 \\
\hline BMI $\left(\mathrm{kg} / \mathrm{m}^{2}\right)$ & $25.3 \pm 3.3$ & $25.4 \pm 3.3$ & $24.5 \pm 3.1$ & 0.09 & 0.08 \\
\hline Height $(\mathrm{cm})$ & $171.4 \pm 9.2$ & $169.6 \pm 9.7$ & $173.8 \pm 9.6$ & 0.49 & 0.46 \\
\hline Weight (kg) & $74.6 \pm 11.8$ & $73.2 \pm 12.5$ & $71.8 \pm 13.8$ & 0.67 & 0.57 \\
\hline Bicuspid aortic valve & $25(29 \%)$ & $13(28 \%)$ & - & - & - \\
\hline Glucose (mmol/l) & $5.2 \pm 0.8$ & $5.2 \pm 0.7$ & $5.2 \pm 0.2$ & 0.1 & 0.14 \\
\hline Creatinine (umol/l) & $74.8 \pm 12.8$ & $72.9 \pm 11.2$ & $75.4 \pm 8.9$ & 0.32 & 0.41 \\
\hline Total cholesterol (mmol/l) & $5.3 \pm 1.0$ & $5.2 \pm 0.8$ & $5.4 \pm 0.9$ & 0.9 & 0.85 \\
\hline LDL-cholesterol (mmol/l) & $3.0 \pm 0.6$ & $2.9 \pm 0.7$ & $3.0 \pm 0.4$ & 0.8 & 0.99 \\
\hline HDL-cholesterol (mmol/l) & $1.4 \pm 0.3$ & $1.4 \pm 0.3$ & $1.3 \pm 0.2$ & 0.79 & 0.84 \\
\hline Triglycerides $(\mathrm{mmol} / \mathrm{l})$ & $1.4 \pm 0.4$ & $1.3 \pm 0.5$ & $1.3 \pm 0.6$ & 0.8 & 0.67 \\
\hline
\end{tabular}

$B M I$ body mass index

\section{Flow mediated dilatation}

The examination was performed between 8 and 10 a.m. in a temperature-controlled room $\left(20^{\circ}-22^{\circ} \mathrm{C}\right)$ with subjects resting in a supine position. Conduit-vessel endothelial function was assessed using the ultrasound measurement of brachial artery diameter (Bad) during changes in brachial artery flow (7-12 MHz linear array transducer, Logic 7, GE). A 5-cm length of the brachial artery was imaged in a longitudinal section above the antecubital fossa and with the optimal probe site marked on the skin. Baseline images of Bad and Doppler velocities from the center of the vessel were recorded. A distal-occluding forearm cuff placed just below the antecubital fossa was inflated to $50 \mathrm{mmHg}$ above the systolic pressure for $5 \mathrm{~min}$. A brachial artery scan was then obtained for $120 \mathrm{~s}$ after the cuff deflation, including a repeated flow velocity recording for the first $15 \mathrm{~s}$ after the cuff release. After $10 \mathrm{~min}$ of rest, sublingual nitroglycerin $(0.5 \mathrm{mg})$ was administrated to determine the maximum obtainable exogenous vasodilatatory response. Bad and blood flow were measured following NTG. The response of the vessel diameter to reactive hyperemia [flow-mediated dilatation (FMD)] was calculated and expressed as the percentage change relative to the diameter measured immediately before the cuff inflation. The diameter change caused by nitroglycerin was expressed as the percentage change relative to the recovery scan [nitroglycerin-mediated dilatation (NMD)] [12].

\section{IMT B-mode carotid ultrasound}

Carotid scans were performed using a Logic 7, GE ultrasound machine with the $7-12 \mathrm{MHz}$ transducer.
Following the acquisition of the scan, the diastolic images with the best demonstrated intimal medial thickening (IMT) were analysed. Both near and far walls of the common carotid artery were visualised on the same scan to ensure the transducer was transecting the artery at $90^{\circ}$. Scans were read by a single observer blinded to the other results. Images were analysed using a quantitative analysis package (Siemens) giving an axial resolution of $0.001 \mathrm{~mm}$. Measurements of IMT were made at $1 \mathrm{~mm}$ intervals over a $10 \mathrm{~mm}$ segments of the vessel. The maximal and mean IMT measurements were determined for the near and far walls of the left and right common carotid arteries [1].

\section{Pulse wave velocity}

For the assessment of the pulse wave velocity (PWV), the pulse wave was obtained over the right radial artery and at the neck for the right common carotid artery. Transit time was measured as the time between the foot of the pulse wave and the $R$ wave in concurrently recorded ECG. The data were collected directly into the laptop (HP Pavillion Entertainment PC). Pulse transit time was determined as the average of consecutive beats during the last $10 \mathrm{~s}$. Time delay $(t)$ was calculated as the difference between those two transit times. The distance $(d)$ travelled by the pulse wave was measured over the body surface at the distance between the two locations. Pulse wave velocity was calculated as $\mathrm{PWV}=d / t \mathrm{~m} / \mathrm{s}$ by the SphygmoCor device (SphygmoCor PVx, Version 8.0, AtCor, Sydney, Australia) [23]. 


\section{Central aortic function assessment}

Central parameters of the aortic pulse wave and arterial wall stiffness of the large conduit arteries were measured using pulse wave analysis performed with applanation tonometry (SphygmoCor PVx, Version 8.0, AtCor, Sydney, Australia). Brachial blood pressure (BP) needed for the algorithm of the procedure was measured non-invasively after $15 \mathrm{~min}$ of rest in the supine position with Omron 705IT device (Omron Healthcare, Kyoto, Japan). For the assessment of the parameters of the central aortic pulse wave, the pulse waveform of the radial artery was recorded for $10 \mathrm{~s}$. and a radial to aortic transfer function was used to derive the central aortic pulse pressure (APP) waveform from which the aortic systolic pressure (ASP), aortic diastolic pressure (ADP), augmentation pressure (AP) and augmentation index (AI) were determined. The central aortic pulse wave peaks twice. The first peak is caused by ejection of blood from the left ventricle and the second is a result of the wave reflected from the periphery, overlapping the primary one. The AP is the difference between the second and the first peak, and the $\mathrm{AI}$ is the ratio of AP to APP expressed as a percentage [22].

\section{Statistics}

Data are presented as the mean value with standard deviation $( \pm \mathrm{SD})$. For variables following normal distribution, statistical analysis was performed with the Student $t$ test for unpaired samples. For variables not following normal distribution, the Mann-Whitney $U$ test was used. To determine the relationship between variables, the Spearmen rank-order or Pearson correlation were analysed. Categorical variables were compared using the chi-square test. Results of $p<0.05$ were considered statistically significant.

Informed consent was obtained from each patient, and our study protocol, as approved a priori by our institution's human research committee, conformed to the ethical guidelines set forth by the 1975 Declaration of Helsinki.

\section{Results}

As shown in Table 2, postcoarctectomy patients had significantly elevated values of both peripheral systolic and diastolic resting blood pressure (SBP and DBP), as compared to the control group $(140.3 \pm 16.7 \quad$ vs. $125.6 \pm 7.0 \mathrm{mmHg} ; \quad p=0.00001$ and $75.2 \pm 9.6$ vs. $69.9 \pm 9.8 \mathrm{mmHg} ; p=0.002$ ). Values of ASP were also significantly increased $(114.9 \pm 13.5$ vs. $102.4 \pm 10.3$ mmHg; $p=0.0003$ ) but ADP did not differ between the groups (70.7 \pm 9.2 vs. $70.2 \pm 9.1 ; p=0.7)$. Central parameters: APP in the studied group was higher than in the control patients $(43.2 \pm 11.9$ vs. $32.1 \pm 9.8 \mathrm{mmHg}$; $p=0.0003)$, similar results were obtained for AP (9.2 \pm 6.0 vs. $4.4 \pm 3.6 \mathrm{mmHg} ; p=0.00002)$ and $\mathrm{AI}(20.3 \pm$ 9.6 vs. $13.5 \pm 4.3 \% ; p=0.003$ ). Postcoarctectomy subjects had substantially increased arterial stiffness, as shown by higher values of PWV $(7.7 \pm 1.7$ vs. $5.4 \pm 0.9 \mathrm{~m} / \mathrm{s}$; $p=0.003)$ and $\operatorname{IMT}(0.63 \pm 0.2$ vs. $0.51 \pm 0.1 \mathrm{~mm}$; $p=0.008$ ). Flow-mediated dilatation after hyperemia, as well as endothelium independent vasodilatation (NMD) were significantly impaired in patients, when compared

Table 2 Vascular characteristics of the entire study population, normotonic coarctation repair patients and comparison to the control group

\begin{tabular}{lccclc}
\hline & $\begin{array}{l}\text { CoAo } \\
(N=85)\end{array}$ & $\begin{array}{l}\text { CoAo AH(-) } \\
(N=47)\end{array}$ & $\begin{array}{l}\text { Controls } \\
(N=30)\end{array}$ & $\begin{array}{l}p \text { CoAo versus } \\
\text { controls }\end{array}$ & $\begin{array}{c}p \text { CoAo AH(-) } \\
\text { versus controls }\end{array}$ \\
\hline HR (beats/min) & $70.6 \pm 11.8$ & $70.5 \pm 9.2$ & $69.4 \pm 10.4$ & 0.2 & 0.2 \\
SBP at rest (mmHg) & $140.3 \pm 16.7$ & $125.5 \pm 9.2$ & $120.6 \pm 7.0$ & 0.00001 & 0.45 \\
DBP at rest (mmHg) & $75.2 \pm 9.6$ & $73.3 \pm 9.9$ & $69.9 \pm 9.8$ & 0.002 & 0.35 \\
ASP (mmHg) & $114.9 \pm 13.5$ & $110.8 \pm 10.8$ & $102.4 \pm 10.3$ & 0.0003 & 0.0005 \\
ADP (mmHg) & $70.7 \pm 9.2$ & $70.5 \pm 8.7$ & $70.2 \pm 9.1$ & 0.7 & 0.95 \\
APP (mmHg) & $43.2 \pm 11.9$ & $39.6 \pm 8.8$ & $32.1 \pm 9.8$ & 0.00001 & 0.0001 \\
AP (mmHg) & $9.2 \pm 6.0$ & $7.3 \pm 4.6$ & $4.4 \pm 3.6$ & 0.00002 & 0.002 \\
AI $(\%)$ & $20.3 \pm 9.6$ & $18.6 \pm 10.4$ & $13.5 \pm 4.3$ & 0.0002 & 0.03 \\
PWV (m/s) & $7.7 \pm 1.7$ & $6.8 \pm 1.2$ & $5.4 \pm 0.9$ & 0.0003 & 0.03 \\
IMT (mm) & $0.63 \pm 0.2$ & $0.51 \pm 0.1$ & $0.51 \pm 0.1$ & 0.008 & 0.06 \\
FMD (\%) & $4.9 \pm 3.4$ & $4.8 \pm 2.8$ & $8.5 \pm 2.3$ & 0.00005 & 0.00003 \\
NTG (\%) & $10.6 \pm 5.2$ & $11.3 \pm 4.6$ & $19.8 \pm 7.2$ & 0.00001 & 0.00001
\end{tabular}

CoAo patients after coarctation repair, $C O A o A H(-)$ normotonic coarctation repaired patients, $H R$ heart rate, $S B P$ systolic blood pressure, $D B P$ diastolic blood pressure, $A S P$ central systolic pressure, $A D P$ central diastolic pressure, $A P P$ central pulse pressure, $A P$ augmentation pressure, $A I$ augmentation index, $P W V$ pulse wave velocity, $I M T$ intima-media thickness, $F M D$ flow-mediated dilatation, $N M D$ nitroglycerin-mediated vasodilatation 
Table 3 Baseline

characteristics and comparison of patients with respect to the presence of recoarctation

\begin{tabular}{llll}
\hline & $\begin{array}{l}\operatorname{AoD}(+) \\
(N=46)\end{array}$ & $\begin{array}{l}\operatorname{AoD}(-) \\
(N=39)\end{array}$ & $\begin{array}{l}p \text { AoD }(+) \text { versus } \\
\operatorname{AoD}(-)\end{array}$ \\
\hline Male:female & $20: 16$ & $33: 16$ & 0.24 \\
Age (years) & $33.5 \pm 10.4$ & $35.8 \pm 10.4$ & 0.54 \\
Age at surgery (years) & $12.4 \pm 7.9$ & $9.4 \pm 8.0$ & 0.04 \\
Smoker (current) & $4(8.6 \%)$ & $2(5.1 \%)$ & 0.64 \\
BMI $\left(\mathrm{kg} / \mathrm{m}^{2}\right)$ & $25.0 \pm 3.0$ & $25.6 \pm 3.6$ & 0.08 \\
Height $(\mathrm{cm})$ & $173.5 \pm 8.6$ & $170.8 \pm 9.5$ & 0.48 \\
Weight $(\mathrm{kg})$ & $75.5 \pm 11.5$ & $73.2 \pm 12.5$ & 0.67 \\
Glucose $(\mathrm{mmol} / \mathrm{l})$ & $5.3 \pm 0.6$ & $5.2 \pm 0.6$ & 0.13 \\
Creatinine $(\mathrm{umol} / \mathrm{l})$ & $76.9 \pm 13.1$ & $72.2 \pm 12.2$ & 0.32 \\
Total cholesterol $(\mathrm{mmol} / \mathrm{l})$ & $5.2 \pm 0.9$ & $5.4 \pm 0.7$ & 0.91 \\
LDL-cholesterol $(\mathrm{mmol} / \mathrm{l})$ & $2.9 \pm 0.8$ & $3.0 \pm 0.7$ & 0.78 \\
HDL-cholesterol(mmol/l) & $1.3 \pm 0.2$ & $1.4 \pm 0.4$ & 0.83 \\
Triglycerides $(\mathrm{mmol} / \mathrm{l})$ & $1.3 \pm 0.5$ & $1.5 \pm 0.9$ & 0.79 \\
\hline
\end{tabular}

with the controls $(4.9 \pm 3.4$ vs. $8.5 \pm 2.3 \% ; p=0.00005$ and $10.6 \pm 5.2$ vs. $19.8 \pm 7.2 \% ; p=0.00001)$.

Forty-seven patients after CoAo repair had normal blood pressure [CoAo $\mathrm{AH}(-)]$. Comparison with the controls revealed differences in central parameters- $\mathrm{APP}(39.6 \pm 8.8$ vs. $32.1 \pm 9.8 \mathrm{mmHg} ; p=0.0001)$, $\mathrm{AP}(7.3 \pm 4.6$ vs. $4.4 \pm 3.6 \mathrm{mmHg} ; p=0.002)$ and $\mathrm{AI}(18.6 \pm 10.4$ vs. $13.5 \pm 4.3 \% ; p=0.03)$ in the studied normotensives were significantly higher than among controls. Peripheral vessel parameter analysis showed that PWV of CoAo $\mathrm{AH}(-)$ patients was higher than in the control group ( $6.8 \pm 1.2 \mathrm{vs.}$ $5.4 \pm 0.9 \mathrm{~m} / \mathrm{s} ; \quad p=0.003)$, but IMT was comparable $(0.53 \pm 0.1$ vs. $0.51 \pm 0.1 \mathrm{~mm} ; p=0.06)$. The studied group revealed lesser degree of vasodilatation as expressed in values of FMD $(4.8 \pm 2.8$ vs. $8.5 \pm 2.3 \% ; p=0.00003)$ and $\operatorname{NMD}(11.3 \pm 4.6$ vs $19.8 \pm 7.2 \% ; p=0.00001)$.

Residual stenosis of the AoD was found in 46 patients $[\mathrm{AoD}(+)]$, their pressure gradient ranged from 20.0 to $70.0 \mathrm{mmHg}$ (mean $35.3 \pm 11.9 \mathrm{mmHg}$ ), and systolic arm to leg gradient from 20 to $61 \mathrm{mmHg}$ (mean $36.7 \pm$ $13.9 \mathrm{mmHg})$. In the remaining 39 patients $[\operatorname{AoD}(-)]$, the pressure gradient ranged from 4.0 to $19.0 \mathrm{mmHg}$ (mean $16.2 \pm 6.1 \mathrm{mmHg}$ ) and systolic arm to leg gradient respectively, -4 to $17 \mathrm{mmHg}(4.8 \pm 8.6 \mathrm{mmHg})$. Demographic characteristics of analysed groups of patients are presented in Table 3. AoD $(+)$ patients were matched for age $(35.5 \pm 10.4$ vs. $33.8 \pm 10.4$ years; $p=0.54$ ) and number of smokers ( 8.6 vs. $5.1 \% ; p=0.69)$. There was also no difference between the groups in BMI ( $25.0 \pm 3.0$ vs. $\left.26.6 \pm 3.6 \mathrm{~kg} / \mathrm{m}^{2} ; p=0.08\right)$, weight (75.5 \pm 11.5 vs. $73.2 \pm 12.5 \mathrm{~kg} ; p=0.67)$, height $(173.5 \pm 8.6$ vs. $170.8 \pm 9.5 \mathrm{~cm} ; p=0.48)$, neither in the biochemical parameters. The only parameter differing between the groups was the age at the time of surgical
Table 4 Vascular characteristics and comparison of patients with respect to the presence of recoarctation

\begin{tabular}{llll}
\hline & $\begin{array}{l}\text { AoD }(+) \\
(N=46)\end{array}$ & $\begin{array}{l}\operatorname{AoD}(-) \\
(N=39)\end{array}$ & $\begin{array}{l}p \operatorname{AoD}(+) \\
\text { versus AoD }(-)\end{array}$ \\
\hline HR (beats/min) & $69.8 \pm 13.4$ & $71.6 \pm 6.7$ & 0.47 \\
SBP (mmHg) & $143.3 \pm 14.7$ & $136.6 \pm 14.9$ & 0.06 \\
DBP (mmHg) & $81.2 \pm 9.3$ & $79.1 \pm 10.1$ & 0.99 \\
Hypertonics $(\%)$ & $4(8.6 \%)$ & $2(5.1 \%)$ & 0.69 \\
ASP (mmHg) & $116.3 \pm 14.2$ & $110.0 \pm 12.0$ & 0.05 \\
ADP $(\mathrm{mmHg})$ & $72.6 \pm 9.9$ & $69.3 \pm 9.9$ & 0.09 \\
APP (mmHg) & $46.7 \pm 13.8$ & $38.3 \pm 6.9$ & 0.001 \\
AP (mmHg) & $10.5 \pm 6.9$ & $7.5 \pm 4.1$ & 0.02 \\
AI $(\%)$ & $21.0 \pm 8,5$ & $19.3 \pm 8.5$ & 0.44 \\
PWV (m/s) & $7.6 \pm 1.3$ & $7.8 \pm 2.0$ & 0.49 \\
IMT (mm) & $0.67 \pm 0.2$ & $0.64 \pm 0.1$ & 0.45 \\
FMD $(\%)$ & $4.6 \pm 3.2$ & $5.1 \pm 3.9$ & 0.06 \\
NTG $(\%)$ & $10.5 \pm 5.2$ & $10.8 \pm 5.0$ & 0.75
\end{tabular}

CoAo patients after coarctation repair, CoAo $A H(-)$ normotonic coarctation repaired patients, $H R$ heart rate, $S B P$ systolic blood pressure, $D B P$ diastolic blood pressure, $A S P$ central systolic pressure, $A D P$ central diastolic pressure, $A P P$ central pulse pressure, $A P$ augmentation pressure, $A I$ augmentation index, $P W V$ pulse wave velocity, IMT intima-media thickness, FMD flow-mediated dilatation, $N M D$ nitroglycerin-mediated vasodilatation

procedure- $\mathrm{AoD}(-)$ patients were operated on earlier than $\mathrm{AoD}(+)$ patients $(12.4 \pm 7.9$ vs. $9.4 \pm 8.0$ years; $p=0.04)$.

As shown in Table 4, resting SBP and DBP did not differ between the subgroups with and without residual gradient in the $\mathrm{AoD}(143.3 \pm 14.7$ vs. $136.6 \pm 14.9 \mathrm{mmHg} ; p=0.06$ and $81.2 \pm 9.3$ vs. $79.1 \pm 10.1 \mathrm{mmHg} ; p=0.99$ ), as well as the number of patients with hypertension ( $40.5 \mathrm{vs.} 47.9 \%$, $p=0.64)$. Central parameters: comparing patient groups $\mathrm{AoD}(+)$ and $\mathrm{AoD}(-)$ showed that ASP was higher in 
Table 5 Correlations between arterial parameters and current age, age at the operation and gradient across the descending aorta

\begin{tabular}{llll}
\hline & Current age & Age at operation & AoD gradient \\
\hline APP & $p=0.001$ & NS & NS \\
& $r=0.3605$ & & \\
AP & $p=0.00007$ & NS & $p=0.01$ \\
& $r=0.4443$ & & $r=0.259$ \\
AI & $p=0.00007$ & NS & NS \\
& $r=0.617$ & & \\
FMD & NS & NS & NS \\
NMD & NS & NS & NS \\
IMT & NS & NS & NS \\
PWV & NS & NS & NS \\
\hline
\end{tabular}

$A P P$ aortic pulse pressure, $A P$ augmentation pressure, $A I$ augmentation index, $P W V$ pulse wave velocity, IMT intima-media thickness, $F M D$ flow-mediated dilatation, NMD nitroglycerin-mediated vasodilatation

patients with recoarctation but this elevation did not reach statistical significance $(116.3 \pm 14.2$ vs. $111.0 \pm 12.0$ $\mathrm{mmHg} ; p=0.05$ ), while ADP did not differ between the groups (72.6 \pm 9.9 vs. $69.3 \pm 9.9 \mathrm{mmHg} ; p=0.09)$. APP as well as AP were higher in patients with recoarctation ( $46.7 \pm 13.8$ vs. $38.3 \pm 6.9 ; p=0.001$ and $10.5 \pm 6.9$ vs. $7.5 \pm 4.1 ; p=0.02)$. Such difference was not observed comparing AI $(21.0 \pm 8.8$ vs. $19.3 \pm 8.5 \% ; p=0.44)$. Variables concerning arterial stiffness PWV and IMT $(7.6 \pm 1.3$ vs. $7.8 \pm 2.0 \mathrm{~m} / \mathrm{s} ; p=0.49$ and $0.67 \pm 0.2$ vs. $0.64 \pm 0.1 \mathrm{~mm} ; p=0.45$ ) were compared between both subgroups. There were no differences in endothelium dependent-vasodilatation (FMD), as well as endothelium independent vasodilatation (NMD) $(4.5 \pm 3.2$ vs. $5.2 \pm$ $3.4 \% ; p=0.06$ and $10.5 \pm 5.2$ vs. $10.8 \pm 5.0 \% ; p=0.75$ ).

Linear correlation analysis of results for the entire study group concerning current age, age at the operation, gradient across the AoD and analysed vascular parameters showed significant positive correlation between current age and APP $(r=0.361 ; p=0,001), \quad$ AP $\quad(r=0.444 ; \quad p=$ $0.00002)$, as well as AI $(r=0.481 ; p=0.00001)$. Gradient across the AoD correlated positively with AP $(r=0.295 ; p=0.01)$. There was no significant linear correlation between age at the time of surgery and any of peripheral arterial parameters (Table 5).

\section{Discussion}

Long-term follow-up shows that despite successful repair, post-CoAo subjects are at high risk of $\mathrm{AH}$ and subsequent end-organ complications [7, 12, 24, 25]. An important pathogenetic link between these phenomena are changes in arterial morphology and reactivity $[2,3,12,19,22,24$, 26-c32]. It still remains to be unresolved, whether vascular remodeling is an inherent part of this congenital condition or results from increased blood pressure values [10, 21, 33]. Gidding et al. [34] were first to show enhanced vasoconstriction of the forearm arteries of CoAo patients, with no such response in the vessels of the lower part of the body, and that confirmed functional and morphological autonomy of the precoarctation arterial tree. Our study confirms presence of advanced vascular pathology in this group of patients. To eliminate the influence of hypertension as a causative factor, the analysis was limited to data obtained from normotensive subjects. As described by the majority of authors [2, 12, 22, 24, 26-28, 30], in this population of patients reduced responses are present of both, endothelium dependent arterial relaxation (FMD) in the brachial artery and nitroglycerine-mediated vasodilatation (NMD) reflecting depleted diastolic capability due to reduced capacity for relaxation of vascular smooth muscle cells or structural changes in the arterial wall. Increased stiffness of precoarctation arteries in postcoarctectomy patients is confirmed by higher values of PWV found in our study, a parameter which is considered to be a robust index of arterial stiffness. Similar conclusions were drawn by both de Divitiis et al. [12] and Ou et al. [9]. On the other hand, our study found no differences in intima-media thickness (IMT), which corresponds to results of Swan et al. [1], but was not confirmed by others [17, 24]. What is more, Meyer et al. [2] reported significantly higher IMT in children, which may validate congenital character of vascular changes in CoAo. It is important, that the pathological values of peripheral vascular parameters in the study are established risk factors for serious cardiovascular events (stroke, coronary artery disease, general cardiac mortality) $[35,36]$. Similar prognostic value was determined for both $\mathrm{AP}$ and $\mathrm{AI}$-indicators of increased ASP, reflecting total vascular stiffness [37]. Our study point towards a significant increase in those parameters in patients after CoAo repair, which was also previously reported by Chen et al. [22]. Swan et al. [1] reported that only values of central arterial pulse pressure (APP) were higher than in the healthy population. Those authors underline the usefulness of central vascular parametersfacilitating early evaluation of the risk of potential subendocardial ischemia in the left ventricle, resulting from early returned arterial wave, following increased stiffness of precoarctation arterial tree $[1,21]$. Our analysis confirms the thesis that vascular remodeling in patients after CoAo repair is a phenomenon independent of $\mathrm{AH}[3,10,21,22$, 26]. The majority of scientists in that field claim that intrinsic abnormalities of the aortic wall and functional abnormalities in vascular reactivity may lead to hypertension and simultaneously positive feedback can be provided by hypertension itself by enhancing this remodeling $[3,10$, $14,22]$. 
There is no agreement on the role of residual gradient in the AoD. Although some researchers report that recoarctation influences value of blood pressure [17, 38], still most authors find no association between $\mathrm{AH}$ and discreet residual aortic narrowing $[3,8,11,12]$, which stands in line with the results achieved in our analysis. We have found no association between $\mathrm{AH}$ and discreet residual aortic narrowing. The results of our study revealed no significant differences in stiffness and reactivity parameters between patients with and without recoarctation. Moreover, there have been no relevant correlations between those parameters and transaortic gradient. Meyer et al. [2] also reported no link between peripheral arterial reactivity and the level of recoarctation in children operated for CoAo. On the other hand, our patients with residual AoD gradient showed higher values of augmentation and central pulse pressure. The results of those parameters point to increased aortic wall stiffness as well as abnormal wave transmission. In healthy individuals with normal aorta, reflected wave comes only from distal vasculature, while after CoAo repair pressure waves are reflected not only from the distal part of the vascular bed but also proximally-from the site of obstruction [1, 22]. This phenomenon could be partly responsible for increase in the values of central parameters revealed in patients with recoarctation, as well as an important link between AP and transaortic gradient. Observed in our study, lack of correlation between the residual narrowing of $\mathrm{AoD}$ and parameters of peripheral remodeling confirms the thesis that hypertension in CoAo patients is not associated with a mechanical obstruction but rather with the primary stiffness of proximal aortic segment, resulting from an increase in collagen and a decrease in smooth muscle cells present in the aortic wall $[3,9,10$, 19, 32]. The reduced elastic properties of the precoarctation aorta lead to permanent abnormalities in baroreceptor readaptation [3, 9, 10, 21, 29, 39]. Although Vriend et al. [17] claim that interventional dilatation should be performed even in case of small residual narrowing of AoD, Chen et al. [22] have not shown any improvement in the peripheral arterial remodeling parameters in patients following stent implantation at the site of stenosis, which in turns seems to support the results obtained in our study.

Undoubtedly, CoAo repair significantly improved prognosis of patients with this congenital heart disease and long-term observation reveal that prevalence of hypertension and overall mortality depend on the age at the time of surgery [5, 13, 14, 22, 33]. However, an increasing number of researchers support the thesis that even an early operation may not alter the course of this cardiovascular disease and will not prevent harmful vascular changes in those patients [10, 21]. Our analysis revealed no relationship between age at the operation and arterial reactivity expressed as FMD and NMD, which confirms earlier findings [2, 12, 26]. Heger et al. [27] claim that higher FMD and NMD were observed in patients operated on before the age of nine but at the same time they report no significant correlation of those parameters with the age at the surgery. On the contrary to de Divitiis et al. [12], our study failed to identify the link between PWV and IMT or age at the operation. These observations suggest early determination of vascular changes in CoAo patients, the mechanism which is likely dependent on potential genetic or intrauterine factors [21, 40].

Our study showed that parameters related to central pressure pulse wave-AP, AI and APP_-do correlate with the current age of patients, which is true in general for the aging population [35], but they do not display any relationship to the age at the surgery. Increased compliance of precoarctation aorta after removal of mechanical obstruction was clearly obtained by Brili et al. [29]. Yet, Vogt et al. [32] report impaired elastic properties of the ascending aorta even in newborns after successful CoAo repair. It seems that even though central parameters are related to increased general arterial stiffness, pathologic changes characteristic for ascending aorta in CoAo are themselves an important independent determinant of vascular remodeling $[10,20]$. That validates the claim that despite early successful repair permanent impairment of vascular compliance above the place of coarctation might be the cause of vascular and end-organ complications.

\section{Conclusions}

Residual stenosis in the AoD does not affect the arterial vasodilatation nor stiffness in patients after CoAo repair. Early operation has no impact on peripheral vascular remodeling or central pressure which supports the claim that coarctation of the aorta is a systemic vascular disorder which leads to progressive vascular and end-organ damage despite early correction.

Acknowledgments The authors of this manuscript have certified that they comply with the Principles of Ethical Publishing in the International Journal of Cardiology (Coats AJ. Ethical authorship and publishing. Int J Cardiol 2009; 131:149-50).

Open Access This article is distributed under the terms of the Creative Commons Attribution Noncommercial License which permits any noncommercial use, distribution, and reproduction in any medium, provided the original author(s) and source are credited.

\section{References}

1. Swan L, Kraidly M, Vonder Muhll I, Collins P, Gatzoulis MA (2010) Surveillance of cardiovascular risk in the normotensive 
patients with repaired aortic coarctation. Int $\mathrm{J}$ Cardiol 139:283-288

2. Meyer AA, Joharchi MS, Kundt G, Schuff-Werner P, Steinhoff G, Kienast W (2005) Predicting the risk of early atherosclerotic disease development in children after repair of aortic coarctation. Eur Heart J 26:617-622

3. de Divitiis M, Rubba P, Calabrò R (2005) Arterial hypertension and cardiovascular prognosis after successful repair of aortic coarctation: a clinical model for the study of vascular function. Nutr Metab Cardiovasc Dis 15:382-394

4. Hager A, Kanz S, Kaemmerer H, Hess J (2008) Exercise capacity and exercise hypertension after surgical repair of isolated aortic coarctation. Am J Cardiol 101:1777-1780

5. Vriend JW, Mulder BJ (2005) Late complications in patients after repair of aortic coarctation: implication for management. Int $\mathbf{J}$ Cardiol 101:399-406

6. Cook SC, Ferketich AK, Raman SV (2009) Myocardial ischemia in asymptomatic adults with repaired aortic coarctation. Int $\mathbf{J}$ Cardiol 133:95-101

7. Cohen M, Fuster V, Steele PM, Driscoll D, McGoon DC (1989) Coarctation of the aorta. Long-term follow-up and prediction of outcome after surgical correction. Circulation 80:840-845

8. Celermajer DS, Greaves K (2002) Survivors of coarctation repair: fixed but not cured. Heart 88:113-114

9. Ou P, Celermajer DS, Jolivet O, Buyens F, Herment A, Sidi D, Bonnet D, Mousseaux E (2008) Increased central aortic stiffness and left ventricular mass in normotensive young subjects after successful coarctation repair. Am Heart J 155:187-193

10. Oechslin EN (2008) Does a stent cure hypertension? Heart 94:828-829

11. O'Sullivan JJ, Derrick G, Darnell R (2002) Prevalence of hypertension in children after early repair of coarctation of the aorta: a cohort study using casual and 24 hour blood pressure measurement. Heart 88:163-166

12. de Divitiis M, Pilla C, Kattenhorn M, Donald A, Zadinello M, Wallace S, Redington A, Deanfield J (2003) Ambulatory blood pressure, left ventricular mass and conduit artery function late after successful repair of coarctation of the aorta. J Am Coll Cardiol 41:2259-2265

13. Brouwer RM, Erasmus ME, Ebels T, Eijgelaar A (1994) Influence of age on survival, late hypertension, and recoarctation in elective aortic coarctation repair. Including long-term results after elective aortic coarctation repair with a follow-up from 25 to 44 years. J Thorac Cardiovasc Surg 108:525-531

14. Toro-Salazar OH, Steinberger J, Thomas W, Rocchini AP, Carpenter B, Moller JH (2002) Long-term follow-up of patients after coarctation of the aorta repair. Am J Cardiol 89(5):541-547

15. Mancia G, deBacker G, Dominiczak A, Cifkowa R et al. (2007) Guidelines for the management of arterial hypertension: The Task Force for the Management of Arterial Hypertension of the European Society of Hypertension (ESH) and of the European Society of Cardiology (ESC). Eur Heart J 28:1462-1536

16. Seirafi PA, Warner KG, Geggel RL, Payne DD, Cleveland RJ (1998) Repair of coarctation of the aorta during infancy minimizes the risk of late hypertension. Ann Thorac Surg 66:1378-1382

17. Vriend JW, Zwinderman AH, de Groot E, Kastelein JJ, Bouma BJ, Mulder BJ (2005) Predictive value of mild, residual descending aortic narrowing for blood pressure and vascular damage in patients after repair of aortic coarctation. Eur Heart $\mathbf{J}$ 26:84-90

18. Mullen MJ (2003) Coarctation of the aorta in adults: do we need surgeons? Heart 89:3-5

19. Niwa K, Perloff JK, Bhuta SM, Laks H, Drinkwater DC, Child JS, Miner PD (2001) Structural abnormalities of great arterial walls in congenital heart disease: light and electron microscopic analyses. Circulation 103:393-400

20. Brili S, Tousoulis D, Antoniades C, Aggeli C, Roubelakis A, Papathanasiu S, Stefanadis C (2005) Evidence of vascular dysfunction in young patients with successfully repaired coarctation of aorta. Atherosclerosis 182:97-103

21. Swan L, Ashrafian H, Gatzoulis MA (2002) Repair of coarctation: a higher goal? Lancet 359:977-978

22. Chen SS, Donald AE, Storry C, Halcox JP, Bonhoffer P, Deanfield JE (2008) Impact of aortic stenting on peripheral vascular function and daytime systolic blood pressure in adult coarctation. Heart 94:919-924

23. O'Rurke M (1995) Mechanical principles in arterial disease. Hypertension 26:2-9

24. Ou P, Celermayer DS, Mousseaux E, Giron A, Aggoun Y, Szezepanski I, Sidi D, Bonnet D (2007) Vascular remodeling after "successful" repair of coarctation. J Am Coll Cardiol 49:883-890

25. Ou P, Celermajer DS, Raisky O, Jolivet O, Buyens F, Herment A, Sidi D, Bonnet D, Mousseaux E (2008) Angular (Gothic) aortic arch leads to enhanced systolic wave reflection, central aortic stiffness, and increased left ventricular mass late after aortic coarctation repair: evaluation with magnetic resonance flow mapping. J Thorac Cardiovasc Surg 135:62-68

26. Gardiner HM, Celermajer DS, Sorensen KE, Georgakopoulos D, Robinson J, Thomas O, Deanfield JE (1994) Arterial reactivity is significantly impaired in normotensive young adults after successful repair of aortic coarctation in childhood. Circulation $89: 1745-1750$

27. Heger M, Willfort A, Neunteufl T, Rosenhek R, Gabriel H, Wollenek G, Wimmer M, Maurer TG, Baumgartner H (2005) Vascular dysfunction after coarctation repaired is related to the age at surgery. Int J Cardiol 99:295-299

28. Guenthard J, Wyler F (1995) Exercise-induced hypertension in the arms due to impaired arterial reactivity after successful coarctation resection. Am J Cardiol 75:814-817

29. Brili S, Dernellis J, Aggeli C, Pitsavos C, Hatzos C, Stefanadis C, Toutouzas P (1998) Aortic elastic properties in patients with repaired coarctation of aorta. Am J Cardiol 82:1140-1143, A10

30. Vriend JW, de Groot E, Mulder BJ (2005) Limited effect of early repair on carotid arterial wall stiffness in adult post-coarctectomy patients. Int J Cardiol 100:335-336

31. Ong CM, Canter CE, Gutierrez FR, Sekarski DR, Goldring DR (1992) Increased stiffness and persistent narrowing of the aorta after successful repair of coarctation of the aorta: relationship to left ventricular mass and blood pressure at rest and with exercise. Am Heart J 123:1594-1600

32. Vogt M, Kühn A, Baumgartner D, Baumgartner C, Busch R, Kostolny M, Hess J (2005) Impaired elastic properties of the ascending aorta in newborns before and early after successful coarctation repair: proof of a systemic vascular disease of the prestenotic arteries? Circulation 111:3269-3273

33. Daniels SR (2001) Repair of coarctation of the aorta and hypertension: does age matter? Lancet 358:89

34. Gidding SS, Rocchini AP, Moorehead C, Schork MA, Rosenthal A (1985) Increase forearm vascular reactivity in patients with hypertension after repair of coarctation. Circulation 3:495-499

35. Antiokainen R, Jusilahti P, Toumilehto J (1998) Systolic blood pressure, isolated systolic hypertension and risk of coronary heart disease, strokes, cardiovascular disease and all-cause mortality in the middle-age population. J Hypertens 16:577-583

36. Alioglu E, Turk UO, Bicak F, Tengiz I, Atila D, Barisik V, Ercan E, Akin M (2008) Vascular endothelial functions, carotid intimamedia thickness, and soluble CD40 ligand levels in dipper and nondipper essential hypertensive patients. Clin Res Cardiol $97: 457-462$ 
37. Nichols WW, Singh BM (2002) Augmentation index as a measure of peripheral vascular disease state. Curr Opin Cardiol 17:543-551

38. Vriend JW, van Montfrans GA, Romkes HH, Vliegen HW, Veen G, Tijssen JG, Mulder BJ (2004) Relation between exercise induced hypertension an sustain hypertension in adult patients after successful repair of aortic coarctation. J Hypertens 22:501-509
39. Sehested J, Baandrup U, Mikkelsen E (1982) Different reactivity and structure of prestenotic and poststenotic aorta in human coarctation. Circulation 6:1060-1065

40. Pabst S, Wollnik B, Rohmann E, Hintz Y, Glänzer K, Vetter H, Nickenig G, Grohé C (2008) A novel stop mutation truncating critical regions of the cardiac transcription factor NKX2-5 in a large family with autosomal-dominant inherited congenital heart disease. Clin Res Cardiol 97:39-42 